\title{
Differential expression of chemokine receptors and their roles in cancer imaging
}

\section{Sridhar Nimmagadda*}

Russell H. Morgan Department of Radiology and Radiological Science, Johns Hopkins University, Baltimore, MD, USA

Edited by:

Medhat M. Osman, Saint Louis

University, USA

\section{Reviewed by:}

Nghi Co Nguyen, Saint Louis

University, USA

Luigi Aloj, Istituto Nazionale Tumori

Fondazione G. Pascale, Italy

\section{*Correspondence:}

Sridhar Nimmagadda, Russell H.

Morgan Department of Radiology and

Radiological Science, Johns Hopkins

Medical Institutions, 1550 Orleans

Street, CRB II, \#4MO7, Baltimore, MD

21231, USA.

e-mail:snimmag1@jhmi.edu
Chemokine/chemokine receptor interactions play diverse roles in cell migration and homeostasis. Emerging evidence suggests that cancer cells co-opt chemokine networks for survival, proliferation, immune evasion, and metastasis. Most of the chemokine receptors are reported to be involved in tumor progression. Given their extensive implication in cancer progression, several chemokine receptor/ligand axes are considered as potential therapeutic targets. This review provides a survey of chemokine receptor expression in cancer and evaluates the potential of chemokine receptor imaging as a tool for molecular characterization of cancer.

Keywords: molecular imaging, metastasis, chemokine receptor, chemokine, cancer

\section{INTRODUCTION}

Chemokine/chemokine receptor interactions play key roles in cell trafficking in host defense mechanisms, in organogenesis, vasculogenesis, and tissue repair. Most chemokines are secreted chemotactic cytokines of $8-12 \mathrm{kDa}$ size. They can be divided into subgroups based on structural and functional characteristics. Structurally, chemokines are classified into four groups (CXC, CX3C, XC, and CC) based on the highly conserved first two of the four cysteine residues at the N-terminus (Zlotnik and Yoshie, 2000). Functionally, chemokines are classified as inflammatory or homeostatic. Inflammatory chemokines (e.g., CXCL8) are induced by inflammatory stimuli to attract polymorphonuclear leukocytes from the circulation to sites of infection or injury. Homeostatic chemokines (e.g., CXCL12), on the other hand, are constitutively expressed and regulate cell trafficking and homing during development and immune surveillance. The 48 known chemokines function by activating the 19 identified cell surface receptors that are seven-transmembrane-spanning proteins of the G-proteincoupled receptor (GPCR) superfamily. The chemokine receptor nomenclature system is based upon the chemokine subclass specificity of the receptor, whereby L (ligand) is replaced by R (receptor; Murphy et al., 2000). Although 6 of the 20 receptors are known to bind to a single ligand, several of the chemokines/receptors exhibit promiscuity and bind to more than one receptor/ligand, usually belonging to a single subclass (Zlotnik, 2006). Since the first report on the involvement of chemokine receptors in metastasis by Muller et al. (2001), significant progress has been made in deciphering their roles in cancer. More than half of the chemokine receptors are implicated in the biology of tumor growth and metastasis. A growing body of literature suggests that most chemokine receptors, as shown in Table 1, including CXCR2, CXCR3, CXCR4, CXCR7, and CCR7 play key roles in cancer cell survival, proliferation, homing, adhesion, tumor angiogenesis, and resistance to conventional and targeted therapies. Several chemokine networks are now considered potential therapeutic targets for cancer. This review focuses on the expression of several chemokine receptors for which there exists significant evidence in support of their roles in tumor biology and their possible uses as diagnostic markers.

\section{CXCR1 AND CXCR2}

CXCR1 and CXCR2 show 77\% homology and considerable structural similarity but have distinct ligand-binding pharmacology (Holmes et al., 1991). CXCR1 binds to CXCL6 and CXCL8. CXCR2 binds several chemokines: CXCL1, CXCL2, CXCL3 (GRO $\alpha, \beta$, and $\gamma$ ), CXCL5 (ENA-78), CXCL6 (GCP2), CXCL7 (NAP2), and CXCL8 (Ahuja and Murphy, 1996; Wolf et al., 1998). In the hematopoietic system, both receptors are expressed on granulocytes, monocytes, and mast cells and on some CD8+ T cells and CD56+ natural killer (NK) cells (Chuntharapai et al., 1994). Functional effects of both the receptors are well characterized for the binding of the inflammatory ligand CXCL8 (IL8) than any other ligand (Waugh and Wilson, 2008). CXCR1 binds only CXCL8 with high affinity, whereas CXCR2 is known to bind all the ligands with high affinity (Waugh and Wilson, 2008).

Both receptors have been shown to play important roles in tumor progression in several cancers. In melanoma, CXCR1 is ubiquitously expressed on tumor cells at all Clark levels however, high levels of CXCR2 expression were observed mostly in high-grade melanomas (Varney et al., 2006; Singh et al., 2009a). Elevated CXCR2 and CXCL8 expression are correlated with high microvessel density, tumor angiogenesis, and metastases (Varney et al., 2006). CXCL8 is also constitutively secreted predominantly by melanoma cells resulting in an autocrine stimulation of cancer cells promoting survival, proliferation, and migratory capabilities (Singh et al., 2010). In advanced prostate cancer specimens, CXCR1, CXCR2, and CXCL8 expression were found to localize 
Table 1 | Chemokine receptor expression in cancer.

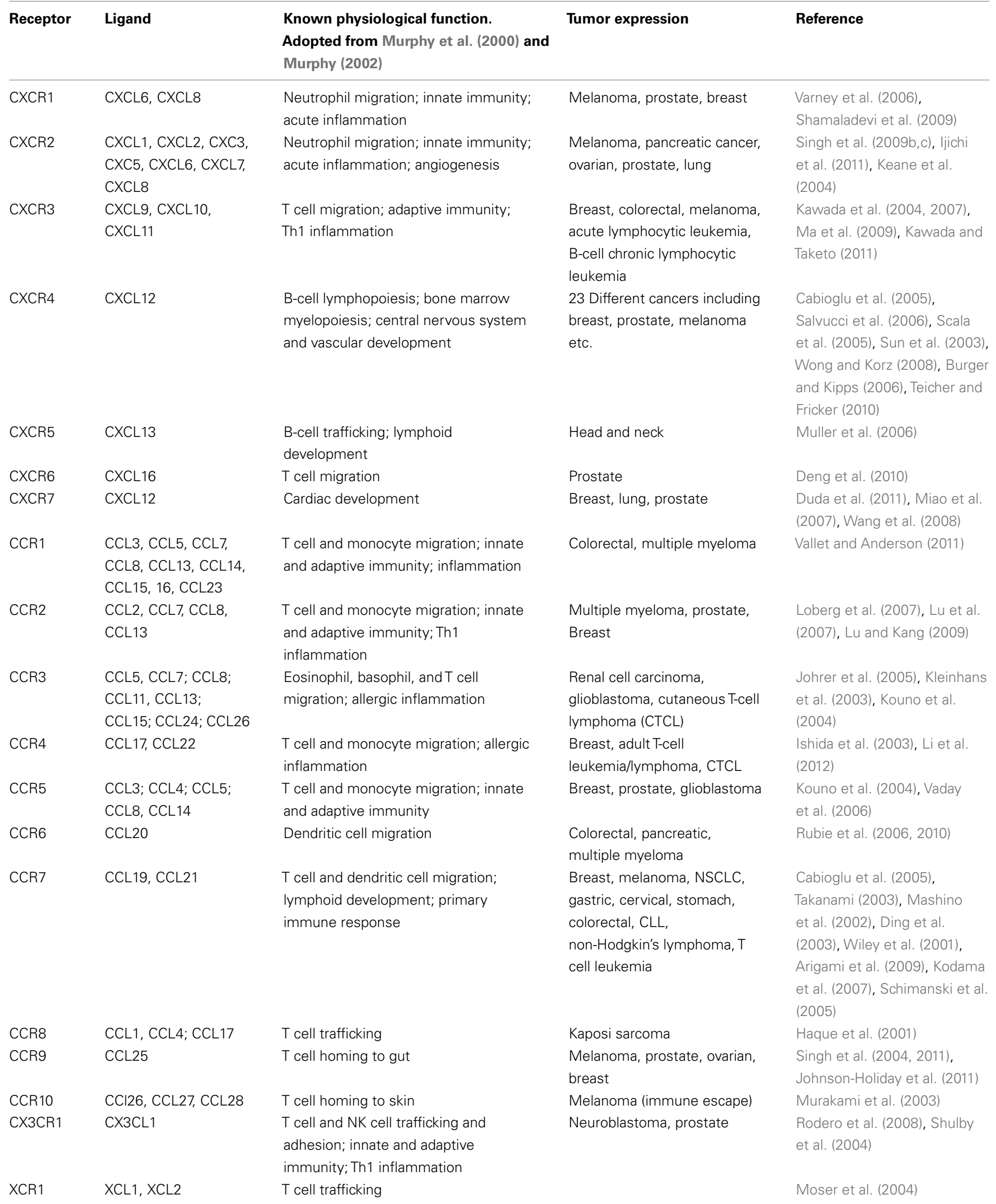


to cytoplasm, and silencing of CXCR1 has been shown to inhibit androgen-independent prostate cancer growth (Shamaladevi et al., 2009). Similarly, CXCR2 has been shown to promote ovarian cancer through dysregulated cell cycle proteins p21 (waf1/cip1), cyclin D1, CDK6, CDK4, cyclin A, and cyclin B1, diminishing apoptosis by suppressing p53 and poly(ADP-ribose) polymerase cleavage, and enhancing angiogenesis by increasing levels of VEGF. CXCR2 expression in high-grade serous ovarian carcinoma was also found to be an independent prognostic factor of poor overall survival and of early relapse in cancer patients (Yang et al., 2010). Furthermore, CXCR1 and CXCR2 overexpression has been shown to increase cancer cell survival in response to hypoxia (Maxwell et al., 2007), and to promote tumor angiogenesis in renal cell carcinoma (Mestas et al., 2005). Not surprisingly, neutralizing antibodies and low molecular weight antagonists targeting these receptors as well as siRNA based downregulation of the receptor expression have been effective in inhibiting tumor growth and invasion in lung, ovarian, pancreatic, and melanoma tumor models (Singh et al., 2009b; Ijichi et al., 2011).

In addition to the cancer cells, activated neutrophils express high levels of CXCR1 and CXCR2 and accumulate at the site of infection and inflammation. This neutrophil accumulation was monitored non-invasively using ${ }^{99 \mathrm{~m}}$ Tc labeled CXCL8 and CXCL7 proteins in different models of infection (Rennen et al., 2004). Despite the availability of a variety of monoclonal antibodies (mAbs) and small molecule structural motifs (Busch-Petersen, 2006) that can be radiolabeled, imaging studies using these agents in cancer have not yet been reported.

\section{CXCR3}

CXCR3 binds CXCL9, CXCL10, and CXCL11 with high affinity, and is expressed by the Th1 T cells, cytotoxic CD8+ T cells, Kupffer cells, endothelial cells, and activated B and NK cells (Garcia-Lopez et al., 2001). CXCR3 expression directs the migration of these cells to inflamed lymph nodes (LN) and other inflamed sites (Liu et al., 2005).

Nearly one third of melanoma (Kawada et al., 2004) and colon cancers (Kawada et al., 2007) and most of all of the breast cancer specimens tested, though to a different degree, were shown to be positive for CXCR3 (Ma et al., 2009). CXCR3 expression in breast and colon cancers and melanoma has been correlated with LN metastases, and considered an independent predictor of poor prognosis (Ma et al., 2009; Kawada and Taketo, 2011). Furthermore, colon cancer patients with tumors positive for both CXCR3 and CXCR4 had a significantly poorer prognosis than those with tumors positive only for CXCR4 or the double negatives, underscoring the importance of evaluating multiple receptors simultaneously (Kawada and Taketo, 2011). In spite of high expression on tumor cells, downregulation of CXCR3 by siRNA, or inhibition by low molecular weight agents was not shown to have an effect on breast or melanoma tumor growth but rather influenced the metastatic ability of the cancer cells to the lungs and LNs (Kawada et al., 2004). Because CXCR3 shows a notable expression on $\mathrm{T}$ cells associated with inflammatory conditions, such as psoriasis, rheumatoid arthritis, diabetes, inflammatory bowel disease, and multiple sclerosis, several antagonists targeting this receptor have been in clinical development (Wijtmans et al., 2008). CXCR3 expression has not yet been imaged and presents an attractive target for imaging.

\section{CXCR4}

CXCR4 is one of the most studied chemokine receptors. CXCR4 is a co-receptor for HIV entry, plays a pivotal role in mediating metastasis in a variety of cancers (Tamamura et al., 2006) and in autoimmune disease. To date, CXCR4 is known to bind only one endogenous ligand, CXCL12 (Zlotnik et al., 2006). CXCL12 expression is ubiquitous and it is highly secreted by stromal cells in lungs, liver, brain, bone marrow, and LNs. CXCR4 is expressed in several tissues (Gupta and Pillarisetti, 1999). The CXCR4-CXCL12 axis is also distinct from many other chemokine networks due to its role in hematopoiesis, organogenesis, and vascularization. CXCR4 or CXCL12 knock-out mice have defects in B-cell lymphopoiesis, bone marrow colonization, and cardiac septum formation resulting in late gestational lethality (Nagasawa et al., 1996; Tachibana et al., 1998).

CXCR4 is over-expressed in nearly 20 types of cancer including breast, brain, lung, ovarian, colon, prostate, and melanoma (Balkwill, 2004). CXCR4 expression in tumor cells is markedly higher compared to many normal tissues (Cabioglu et al., 2009; Duda et al., 2011) and CXCR4 expression is regulated by many tumorassociated factors: at the transcriptional level by hypoxia, NFKB, and Yin Yang 1; at the translational level by HER-2; and at the posttranslational level by E3 ubiquitin ligase and HER-2 (Luker and Luker, 2006). Elevated CXCR4 expression in tumors has been associated with an aggressive phenotype (Cabioglu et al., 2005; Kang et al., 2005; Kim et al., 2005). Overexpression of CXCR4 in primary tumors is directly correlated to increased risk for local recurrence, distant metastasis, and poor survival rates in breast, colon, and several other cancers (Cabioglu et al., 2005; Kim et al., 2005; Scala et al., 2005; Luker and Luker, 2006; Salvucci et al., 2006). In addition to primary tumors, metastases frequently exhibit increased CXCR4 expression, which may offer a new strategy for their early detection (Sun et al., 2003; Salvucci et al., 2006). The hypothesis is that CXCR4 expression enables tumor cells to home to organs expressing abundant levels of CXCL12 such as lungs, liver, brain, and bone marrow leading to establishment of metastases. Neutralizing CXCR4 chemotaxis using low molecular weight agents, peptides, antibodies, or biological agents such as siRNA, reduces the migratory capacity of cancer cells in vitro and metastatic burden in vivo in preclinical models (Liang et al., 2004; Smith et al., 2004; Wong and Korz, 2008).

In addition to the regular GPCR signaling-based activation of multiple downstream targets, the CXCR4-CXL12 axis is also known to be involved in several other pathways. It can transactivate HER-2 receptor (Li et al., 2004; Luker and Luker, 2006) and mediate estrogen-independent tumorigenesis, metastasis, and resistance to endocrine therapy (Rhodes et al., 2011). Similarly, migratory effects induced by epidermal growth factor receptor and insulin-like growth factor signaling cascades in cancer cells requires CXCR4 activation (Akekawatchai et al., 2005; Phillips et al., 2005). Recent studies have also identified increased expression of CXCR4 and CXCL12 in cancer-associated fibroblasts (CAFs). CAFs play an important role in tumorigenesis and are implicated in neoplastic progression, tumor growth, angiogenesis, 
and metastasis (Orimo and Weinberg, 2006). CXCL12 secreted by CAFs not only stimulates carcinoma cell growth directly through the CXCR4 receptor displayed on tumor cells but also recruits endothelial progenitor cells (EPCs) into tumors, thereby furthering angiogenesis (Kojima et al., 2010). Overall, the CXCR4CXCL12 axis plays an active role in tumor resistance to conventional as well as targeted therapies by directly promoting cancer cell survival, invasion, and cancer stem and/or tumor-initiating cell phenotype; by recruiting myeloid bone marrow-derived cells to facilitate tumor recurrence and metastasis indirectly; by promoting angiogenesis directly or in a paracrine manner; and by providing a metastatic niche for cancer cells in the bone marrow (Duda et al., 2011).

The CXCR4-CXCL12 axis is considered a therapeutic target for cancer and several CXCR4 inhibitors are in Phase-I trials (Wong and Korz, 2008; Duda et al., 2011). In addition to reduced metastatic burden, CXCR4 inhibition has also been shown to synergize chemotherapies in various tumor models (Redjal et al., 2006; Azab et al., 2009). As blocking the CXCR4-CXCL12 pathway becomes a viable strategy to target various solid tumors, considering the large number of normal functions that are affected by the CXCR4CXCL12 axis, development, and evaluation of imaging agents for tracking this pathway in vivo is critical. CXCR4-based imaging agents would be beneficial to: (i) evaluate primary tumors for elevated CXCR4 expression and therapeutic intervention; (ii) screen for secondary metastatic spread to both local and distant sites; and (iii) for therapeutic monitoring.

CXCR4-based imaging agents. Antibodies, peptides, and low molecular weight agents have been used for molecular imaging of CXCR4 expression in tumors.

Monoclonal antibodies are re-gaining attention as radiopharmaceutical imaging agents. To investigate the feasibility of CXCR4based imaging, our group radiolabeled a well-characterized monoclonal mouse anti-human CXCR4 antibody, $12 \mathrm{G} 5$, with ${ }^{125} \mathrm{I}$. 12G5 recognizes a determinant in the first and second extracellular loops of CXCR4 and its specificity to CXCR4 is well established (Baribaud et al., 2001). Single Photon Emission Computed Tomography (SPECT) imaging and biodistribution data showed clear accumulation of $\left[{ }^{125} \mathrm{I}\right] 12 \mathrm{G} 5$ in the tumors compared to isotype matched $\left[{ }^{125} \mathrm{I}\right] \mathrm{IgG}_{2 \mathrm{~A}}$ control antibody. Even though the highest accumulation of radioactivity was seen in the spleen and high non-specific uptake was observed due to the murine antibody background, these results establish the feasibility of using radiolabeled mAbs for imaging CXCR4 expression in tumors (Nimmagadda et al., 2009).

CXCR4 is characterized by a strong negatively charged extracellular surface, therefore most of the CXCR4 binding agents are highly basic and positively charged. A detailed overview of the available CXCR4 binding agents and CXCR4-based imaging agents can be found elsewhere in the literature (Mosley et al., 2009; Woodard and Nimmagadda, 2011). The majority of the CXCR4 targeted imaging agents to date have originated from the polyphemusin-based peptides and cyclam-based low molecular weight agents.

The polyphemusin-based peptide T140 provides the foundation for most of the peptide-based CXCR4 imaging agents. $\mathrm{T} 140$ is a 14-residue peptide with a disulfide bridge (T140) and a potent CXCR4 antagonist (Tamamura et al., 1998). Studies have shown that four aminoacid residues, $\mathrm{Arg}^{2}, \mathrm{~L}-3-(2-$ naphthyl)alanine $(\mathrm{Nal})^{3}, \mathrm{Tyr}^{5}$, and $\mathrm{Arg}^{14}$, in T140 are critical for CXCR4 binding (Tamamura et al., 2000). Like many unprotected peptides, T140 was found to be unstable in serum. To improve the stability, many CXCR4 selective analogs, including those with modifications at each terminus, were synthesized (Tamamura et al., 2006) and labeled with various radionuclides. First within this category of peptides is Ac-TZ14011 with the carboxyl group protected via amidation for stability in vivo and a single amino group $\left(\mathrm{D}-\mathrm{Lys}^{8}\right.$ ) distant from the pharmacophore allowing for conjugation of chelates. Generally, chelation of peptides reduces the affinity of the peptide for its target. ${ }^{111}$ In-DTPA conjugation to AcTZ14011 resulted in nearly sixfold decrease in affinity to CXCR4. Also, a 15- to 200-fold increase in uptake was observed in the liver, kidneys, and spleen (Hanaoka et al., 2006). However, reasonable accumulation observed within the tumors and radioactivity uptake values higher than the muscle or blood led to further development of these peptides as dual modality imaging agents (Kuil et al., 2011). Another amidated analog of T140, the N-terminal 4fluorobenzoyl protected TN14003, was labeled with ${ }^{18} \mathrm{~F}$ using $N$ succinimidyl-4-( $\left.{ }^{18}\right)$ F-fluorobenzoate or with ${ }^{64} \mathrm{Cu}$ through conjugation with DOTA on lysine. Studies in mice harboring Chinese hamster ovarian (CHO) tumor stably expressing CXCR4 showed that CXCR4-positive tumors were distinguishable from control tumors, however, co-injection of unlabeled 4-F-TN14003 was necessary to see increased radioactivity in the CXCR4-positive tumors (Jacobson et al., 2010, 2011). Similarly, CXCL12 radiolabeled with ${ }^{99 \mathrm{~m}} \mathrm{Tc}$ or with near-infrared fluorophores demonstrate poor imaging characteristics in vivo, limiting routine use (Misra et al., 2008; Meincke et al., 2011). Demmer and colleagues, using a highly specific cyclic pentapeptide, recently reported interesting data on a peptide-based imaging agent. The ${ }^{68} \mathrm{Ga}$-DOTA conjugated peptide showed optimal pharmacokinetics for imaging with ${ }^{68} \mathrm{Ga}$, i.e., low liver uptake and faster clearance from the kidneys indicating its potential for clinical translation (Demmer et al., 2011).

Among agents of low molecular weight, the bicyclam AMD3100 was the first non-peptide CXCR4 inhibitor to enter clinical trials and is now used for stem cell mobilization (De Clercq, 2010). Cyclams have the ability to form strong complexes with transition metals such as copper and zinc, enabling development of a radiolabeled analog of AMD3100 and imaging of CXCR4 expression in vivo. Fortuitously, the affinity of AMD3100 increases by sevenfold when chelated to copper. Jacobson et al. and our group have investigated copper-64 radiolabeled AMD3100 (Jacobson et al., 2009; Nimmagadda et al., 2010; Weiss et al., 2012). Using subcutaneous U87 brain tumors ( 2\%, CXCR4+), U87 tumors stably expressing CXCR4 (>95\%)(U87-stb-CXCR4) and orthotopic MDA-MB-231 ( 10\%) and DU4475 ( 90\%) breast cancer xenografts, we have demonstrated the feasibility of imaging graded levels of tumor CXCR4 expression. In these studies $\left[{ }^{64} \mathrm{Cu}\right.$ ]AMD3100-Positron Emission Tomography (PET) displayed distinct accumulation of radioactivity in the U87-stbCXCR4 and DU4475 tumors at $90 \mathrm{~min}$ post-injection of the radiotracer (Nimmagadda et al., 2010). Considerable uptake was observed in the liver and lymphoid organs. Given that CXCR4 is expressed on leukocytes, monocytes and in the liver, accumulation 
of radioactivity in these organs, except for the majority of the uptake in the liver, is due to CXCR4-specific binding as confirmed by blocking studies (Nimmagadda et al., 2010). Because metastases often have elevated levels of CXCR4 expression, using an experimental model of lung metastasis derived from breast cancer cells, we have also demonstrated that $\left[{ }^{64} \mathrm{Cu}\right] \mathrm{AMD} 3100-\mathrm{PET}$ enables non-invasive in vivo visualization of metastases (Nimmagadda et al., 2010).

While $\left[{ }^{64} \mathrm{Cu}\right] \mathrm{AMD} 3100$ shows promise as a PET imaging agent, low affinity for CXCR4 and a scaffold not flexible for the development of ${ }^{18} \mathrm{~F}$-labeled analogs may limit clinical use. A second-generation monocyclam-based CXCR4 inhibitor, AMD3465 (Figure 1), has high affinity $(41.7 \pm 1.2 \mathrm{nM})$, reduced charge and is smaller in size compared to AMD3100 (Bodart et al., 2009; De Silva et al., 2011). Utilizing the aforementioned U87 and U87-stb-CXCR4 glioblastoma model, De Silva and colleagues showed that $\left[{ }^{64} \mathrm{Cu}\right] \mathrm{AMD} 3465$-PET has the highest target selectivity reported for this class of agents (Figure 1). These results were further validated in a colon tumor model (De Silva et al., 2011). More importantly, the pyridine moiety of AMD3465 may allow structural modification for the synthesis of clinically translatable agents.

\section{CXCR7}

Although initially cloned as orphan receptor Receptor Dog cDNA 1 (RDC1) in 1990 (Libert et al., 1990), RDC1 was renamed CXCR7 once the binding of chemokine ligands CXCL11 and CXCL12 was characterized (Balabanian et al., 2005; Burns et al., 2006). CXCR7 binds to CXCL12 and CXCL11 with high and low affinities, respectively and plays a role in scavenging or sequestering CXCL12 $\alpha$ (Thelen and Thelen, 2008). CXCR7 differs from other chemokine receptors in several ways. The Asp-Arg-Tyr-Leu-Ala-Ile-Val (DRYLAIV) motif at the second intracellular loop of chemokine receptors, required for coupling a chemokine receptor to Gai-signaling proteins, is altered in CXCR7and its sensitivity to pertussis toxin has not been completely characterized (Thelen and Thelen, 2008). However, similar to other chemokine receptor signaling, CXCR7 stimulation by CXCL12 has been shown to induce the phosphorylation of both MAPK and Akt (Miao et al., 2007; Hartmann et al., 2008). In the hematopoietic system, CXCR7 is expressed by the neutrophils, monocytes, and B-cells. CXCR7 is required for the proper development of the heart, particularly cardiac valves (Sierro et al., 2007). Even though CXCR7 is poorly expressed in nontransformed tissues, increased CXCR7 expression was observed in transformed cells (Burns et al., 2006).

CXCR7 expression on breast, lung, and prostate cancer cells positively correlates with their proliferation, vascularization, and metastatic potential (Miao et al., 2007). CXCR7 is highly expressed on tumor-associated vasculature and not on normal endothelium suggesting a role in tumor angiogenesis (Miao et al., 2007; Mazzinghi et al., 2008). Blockade of CXCR7 signaling using low molecular weight agents, antibodies or siRNA results in smaller tumors and reduced metastatic dissemination in preclinical models (Miao et al., 2007). CXCR7 expression is also regulated by CXCR4 suggesting that combined blockade of CXCR4 and CXCR7 may have synergistic therapeutic effects. Imaging agents specific for CXCR7 have not been reported even though CXCL12 labeled with a near-infrared fluorophore has been used recently for in vivo imaging (Meincke et al., 2011). The availability of mAbs and low molecular weight agents present an opportunity for imaging this important target.

\section{CCR7}

Of the CC family receptors only CCR7, due to its pivotal role in directing LN metastasis, will be discussed in this review. CCR7 binds two ligands, CCL21 and CCL19, which are secreted in LNs. CCR7 is highly expressed by naïve T cells and dendritic cells and is required for homing these cells to the LNs for initiating an adaptive immune response (Forster et al., 2008). CCR7 is also one of the well-characterized receptors with respect to its role in the formation of secondary lymphoid structures (Muller et al., 2003).

CCR7 has been shown to be over-expressed in several cancers including breast, non-small cell lung cancer, esophageal, gastric, and chronic lymphocytic leukemia (Holmes et al., 1991; Muller et al., 2001; Mashino et al., 2002; Ding et al., 2003; Takanami, 2003; Zlotnik, 2006). CCR7 expression correlates with decreased survival of patients with colorectal cancer (Gunther et al., 2005). Unlike CXCR4, CCR7 expression on tumor cells mostly correlates with LN metastasis. Given the role of CCR7 in directing the lymphocytes to the LNs, this observation suggests the possible
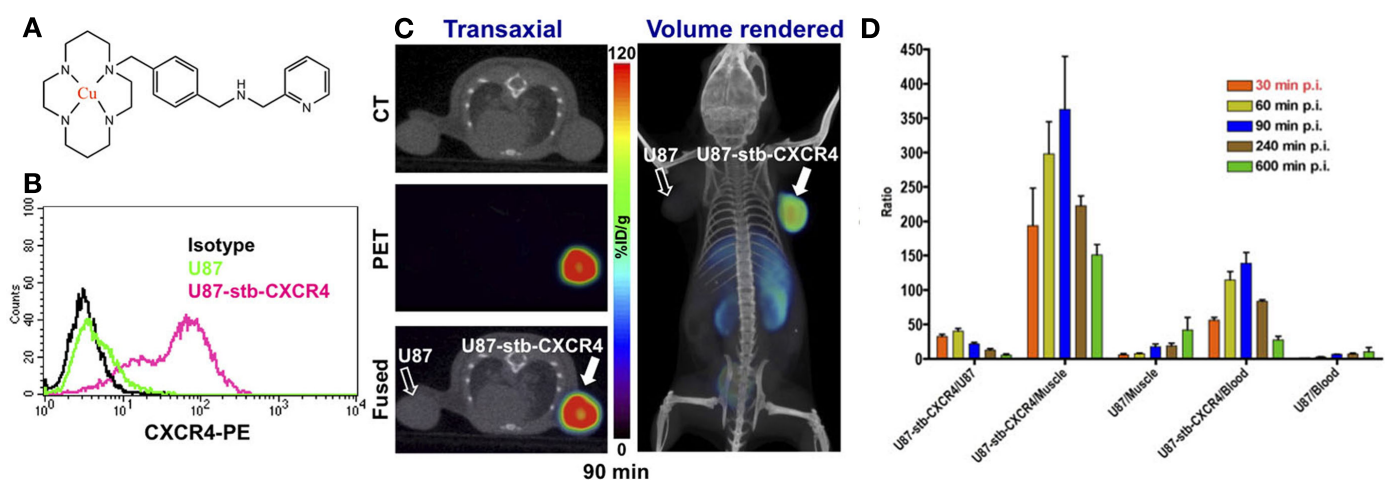

FIGURE 1 | (A) Structure of $\left[{ }^{64} \mathrm{Cu}\right] A M D 3465 ;$ (B) Surface CXCR4 expression in U87 and U87-stb-CXCR4 cells by flow cytometry; (C) PET/CT imaging of CXCR4 expression in subcutaneous brain tumor xenografts with $\left[{ }^{64} \mathrm{Cu}\right] \mathrm{AMD} 3465$ (De Silva et al., 2011). (D) Tumor-to-muscle, tumor-to-blood, and tumor-to-tumor ratios from biodistribution studies of $\left[{ }^{64} \mathrm{Cu}\right] \mathrm{AMD} 3465$ in subcutaneous brain tumor xenografts. 
usurpation of the chemokine receptor pathway by the cancer cells. Furthermore, it has been shown that transfection of breast and melanoma cancer cells with CCR7 shifts the metastasis from lung to LNs (Wiley et al., 2001; Cunningham et al., 2010). Another study demonstrated that CCR7 expression in tumors is highly correlated with the ability to metastasize to the regional LNs and CCR7negative tumors were rarely observed in the local LNs (Takanami, 2003). Taken together, these results strongly suggest that CCR7 expression is important in metastasis to the LNs and non-invasive imaging agents may help in predicting which tumors will metastasize to the LNs. No imaging studies have been reported for this receptor.

\section{CLINICAL IMPLICATIONS AND FUTURE CHALLENGES}

Since the implication of CXCR4 in the metastatic cascade, considerable progress has been made in establishing the role of various chemokine receptors in tumor biology. The direct involvement of chemokine receptor/ligand networks in tumor development, progression, and immune evasion suggests a potential role for chemokine network based therapeutic agents as adjuvants to existing therapies. Even though several chemokine targeted agents are in use, redundancy in chemokine signaling suggests that receptor-targeted strategies that eliminate redundant functions of chemokine signaling may have a greater effect than agents that solely target the effects of chemokines. Conveniently, many inhibitors of chemokine receptors are also in development for other diseases, such as multiple sclerosis or rheumatoid arthritis, which could be translated to oncology. Because chemokine

\section{REFERENCES}

Ahuja, S. K., and Murphy, P. M. (1996). The CXC chemokines growth-regulated oncogene (GRO) alpha, GRObeta, GROgamma, neutrophil-activating peptide-2, and epithelial cell-derived neutrophilactivating peptide-78 are potent agonists for the type $B$, but not the type A, human interleukin8 receptor. J. Biol. Chem. 271, 20545-20550.

Akekawatchai, C., Holland, J. D., Kochetkova, M., Wallace, J. C., and McColl, S. R. (2005). Transactivation of CXCR4 by the insulin-like growth factor-1 receptor (IGF-1R) in human MDA-MB-231 breast cancer epithelial cells. J. Biol. Chem. 280, 39701-39708.

Arigami, T., Natsugoe, S., Uenosono, Y., Yanagita, S., Arima, H., Hirata, M., Ishigami, S., and Aikou, T. (2009). CCR7 and CXCR4 expression predicts lymph node status including micrometastasis in gastric cancer. Int. J. Oncol. 35, 19-24.

Azab, A. K., Runnels, J. M., Pitsillides, C., Moreau, A. S., Azab, F., Leleu, X., Jia, X., Wright, R., Ospina, B., Carlson, A. L., Alt, C., Burwick, N., Roccaro, A. M., Ngo, H. T., Farag,

receptors/ligands are expressed on multiple cancer cell types, effects of the inhibition of these networks should have broad therapeutic application. The broader tissue expression of the receptors also calls for a continuous evaluation of receptor dynamics within the tumor microenvironment, which offers exciting opportunities as well as challenges to the imaging community. Availability of inhibitors and chemical scaffolds for almost all chemokine receptors provides a solid ground to focus on the development of suitable imaging agents. Even though receptor expression, such as those of CXCR4 and CCR7, is well characterized, there is great need to characterize expression of other chemokine receptors in tumors methodically. Another challenge in translating these imaging agents to the clinic is the possibility of low receptor density on tumor cells that may be lower than the sensitivity of detection of some of the imaging modalities. This is compounded by the fact that significantly higher expression of the target on immune cells may act as "sink" for the imaging agent. Some of these concerns could be evaluated in biologically relevant preclinical models. As chemokine receptor blocking agents move into the clinic for targeted cancer therapy, availability of respective imaging agents will not only improve accuracy and precision of the molecular characterization of cancer but also that of other diseases.

\section{ACKNOWLEDGMENTS}

The author thanks Drs. Martin Pomper and Marie-France Penet for critical reading of the manuscript and acknowledges the grant support from the Elsa U. Pardee Foundation, and the Maryland Technology Development Corporation.

S., Bridger, G. J., Macfarland, R. T., and Fricker, S. P. (2009). Pharmacology of AMD3465: a small molecule antagonist of the chemokine receptor CXCR4. Biochem. Pharmacol. 78, 993-1000

Burger, J. A., and Kipps, T. J. (2006). CXCR4: a key receptor in the crosstalk between tumor cells and their microenvironment. Blood 107, 1761-1767.

Burns, J. M., Summers, B. C., Wang, Y., Melikian, A., Berahovich, R., Miao, Z., Penfold, M. E., Sunshine, M. J., Littman, D. R., Kuo, C. J., Wei, K., McMaster, B. E., Wright, K., Howard, M. C., and Schall, T. J. (2006). A novel chemokine receptor for SDF-1 and I-TAC involved in cell survival, cell adhesion, and tumor development. J. Exp. Med. 203, 2201-2213.

Busch-Petersen, J. (2006). Small molecule antagonists of the CXCR2 and CXCR1 chemokine receptors as therapeutic agents for the treatment of inflammatory diseases. Curr. Top. Med. Chem. 6, 1345-1352.

Cabioglu, N., Sahin, A. A., Morandi, P., Meric-Bernstam, F., Islam, R., Lin, $\mathrm{H}$ Y., Bucana, C. D., Gonzalez-Angulo, A. M., Hortobagyi, G. N., and Cristofanilli, M. (2009). Chemokine receptors in advanced breast cancer: differential expression in metastatic disease sites with diagnostic and therapeutic implications. Ann. Oncol. 20, 1013-1019.

Cabioglu, N., Yazici, M. S., Arun, B., Broglio, K. R., Hortobagyi, G. N., Price, J. E., and Sahin, A. (2005). CCR7 and CXCR4 as novel biomarkers predicting axillary lymph node metastasis in T1 breast cancer. Clin. Cancer Res. 11, 5686-5693.

Chuntharapai, A., Lee, J., Hebert, C. A., and Kim, K. J. (1994). Monoclonal antibodies detect different distribution patterns of IL- 8 receptor A and IL-8 receptor B on human peripheral blood leukocytes. J. immunol. 153, 5682-5688.

Cunningham, H. D., Shannon, L. A., Calloway, P. A., Fassold, B. C., Dunwiddie, I., Vielhauer, G., Zhang, M., and Vines, C. M. (2010). Expression of the $\mathrm{C}-\mathrm{C}$ chemokine receptor 7 mediates metastasis of breast cancer to the lymph nodes in mice. Transl. Oncol. 3, 354-361.

De Clercq, E. (2010). Recent advances on the use of the CXCR4 antagonist plerixafor (AMD3100, Mozobil) and potential of other CXCR4 antagonists as stem cell mobilizers. Pharmacol. Ther. 128, 509-518. 
De Silva, R. A., Peyre, K., Pullambhatla, M., Fox, J. J., Pomper, M. G., and Nimmagadda, S. (2011). Imaging CXCR4 expression in human cancer xenografts: evaluation of monocyclam ${ }^{64} \mathrm{Cu}-\mathrm{AMD} 3465$. J. Nucl. Med. 52, 986-993.

Demmer, O., Gourni, E., Schumacher, U., Kessler, H., and Wester, H. J. (2011). PET imaging of CXCR4 receptors in cancer by a new optimized ligand. Chem. Med. Chem. 6, 1789-1791.

Deng, L., Chen, N., Li, Y., Zheng, H., and Lei, Q. (2010). CXCR6/CXCL16 functions as a regulator in metastasis and progression of cancer. Biochim. Biophys. Acta 1806, 42-49.

Ding, Y., Shimada, Y., Maeda, M., Kawabe, A., Kaganoi, J., Komoto, I., Hashimoto, Y., Miyake, M., Hashida, H., and Imamura, M. (2003). Association of CC chemokine receptor 7 with lymph node metastasis of esophageal squamous cell carcinoma. Clin. Cancer Res. 9, 3406-3412.

Duda, D. G., Kozin, S. V., Kirkpatrick, N. D., Xu, L., Fukumura, D., and Jain, R. K. (2011). CXCL12 (SDF1 $\alpha$ )CXCR4/CXCR7 pathway inhibition: an emerging sensitizer for anticancer therapies? Clin. Cancer Res. 17, 2074-2080

Forster, R., Davalos-Misslitz, A. C., and Rot, A. (2008). CCR7 and its ligands: balancing immunity and tolerance. Nat. Rev. Immunol. 8, 362-371.

Garcia-Lopez, M. A., Sanchez-Madrid, F., Rodriguez-Frade, J. M., Mellado, M., Acevedo, A., Garcia, M. I., Albar, J. P., Martinez, C., and Marazuela, M. (2001). CXCR3 chemokine receptor distribution in normal and inflamed tissues: expression on activated lymphocytes, endothelial cells, and dendritic cells. Lab. Invest. 81, 409-418.

Gunther, K., Leier, J., Henning, G., Dimmler, A., Weissbach, R., Hohenberger, W., and Forster, R. (2005). Prediction of lymph node metastasis in colorectal carcinoma by expression of chemokine receptor CCR7. Int. J. Cancer 116, 726-733.

Gupta, S. K., and Pillarisetti, K. (1999). Cutting edge: CXCR4-Lo: molecular cloning and functional expression of a novel human CXCR4 splice variant. J. Immunol. 163, 2368-2372.

Hanaoka, H., Mukai, T., Tamamura, H., Mori, T., Ishino, S., Ogawa, K., Iida, Y., Doi, R., Fujii, N., and Saji, H. (2006). Development of a 111Inlabeled peptide derivative targeting a chemokine receptor, CXCR4, for imaging tumors. Nucl. Med. Biol. 33, 489-494.
Haque, N. S., Fallon, J. T., Taubman, M. B., and Harpel, P. C. (2001). The chemokine receptor CCR8 mediates human endothelial cell chemotaxis induced by I-309 and Kaposi sarcoma herpesvirus-encoded vMIPI and by lipoprotein(a) - stimulated endothelial cell conditioned medium. Blood 97, 39-45.

Hartmann, T. N., Grabovsky, V., Pasvolsky, R., Shulman, Z., Buss, E. C., Spiegel, A., Nagler, A., Lapidot, T., Thelen, M., and Alon, R. (2008). A crosstalk between intracellular CXCR7 and CXCR4 involved in rapid CXCL12-triggered integrin activation but not in chemokinetriggered motility of human T lymphocytes and CD34+ cells. J. Leukoc. Biol. 84, 1130-1140.

Holmes, W. E., Lee, J., Kuang, W. J., Rice, G. C., and Wood, W. I. (1991). Structure and functional expression of a human interleukin-8 receptor. Science 253, 1278-1280.

Ijichi, H., Chytil, A., Gorska, A. E., Aakre, M. E., Bierie, B., Tada, M., Mohri, D., Miyabayashi, K., Asaoka, Y., Maeda, S., Ikenoue, T., Tateishi, K., Wright, C. V., Koike, K., Omata, M., and Moses, H. L. (2011). Inhibiting Cxcr2 disrupts tumor-stromal interactions and improves survival in a mouse model of pancreatic ductal adenocarcinoma. J. Clin. Invest. 121, 4106-4117.

Ishida, T., Utsunomiya, A., Iida, S., Inagaki, H., Takatsuka, Y., Kusumoto, S., Takeuchi, G., Shimizu, S., Ito, M., Komatsu, H., Wakita, A., Eimoto, T., Matsushima, K., and Ueda, R. (2003). Clinical significance of CCR4 expression in adult T-cell leukemia/lymphoma: its close association with skin involvement and unfavorable outcome. Clin. Cancer Res. 9, 3625-3634.

Jacobson, O., Weiss, I. D., Kiesewetter, D. O., Farber, J. M., and Chen, X. (2010). PET of tumor CXCR4 expression with 4-18F-T140. J. Nucl. Med. 51, 1796-1804.

Jacobson, O., Weiss, I. D., Szajek, L., Farber, J. M., and Kiesewetter, D. O. (2009). ${ }^{64} \mathrm{Cu}-\mathrm{AMD} 3100-\mathrm{a}$ novel imaging agent for targeting chemokine receptor CXCR4. Bioorg. Med. Chem. 17, 1486-1493.

Jacobson, O., Weiss, I. D., Szajek, L. P., Niu, G., Ma, Y., Kiesewetter, D. O., Farber, J. M., and Chen, X. (2011). PET imaging of CXCR4 using copper-64 labeled peptide antagonist. Theranostics 1, 251-262.

Johnson-Holiday, C., Singh, R., Johnson, E., Singh, S., Stockard, C. R., Grizzle, W. E., and Lillard, J. W. Jr. (2011). CCL25 mediates migration, invasion and matrix metalloproteinase expression by breast cancer cells in a CCR9-dependent fashion. Int. J. Oncol. 38, 1279-1285.

Johrer, K., Zelle-Rieser, C., Perathoner, A., Moser, P., Hager, M., Ramoner, R., Gander, H., Holtl, L., Bartsch, G., Greil, R., and Thurnher, M (2005). Up-regulation of functional chemokine receptor CCR3 in human renal cell carcinoma. Clin. Cancer Res. 11, 2459-2465.

Kang, H., Watkins, G., Douglas-Jones, A., Mansel, R. E., and Jiang, W. G. (2005). The elevated level of CXCR4 is correlated with nodal metastasis of human breast cancer. Breast 14 360-367.

Kawada, K., Hosogi, H., Sonoshita, M. Sakashita, H., Manabe, T., Shimahara, Y., Sakai, Y., Takabayashi, A., Oshima, M., and Taketo, M. M. (2007). Chemokine receptor CXCR3 promotes colon cancer metastasis to lymph nodes. Oncogene 26 4679-4688.

Kawada, K., Sonoshita, M., Sakashita, H., Takabayashi, A., Yamaoka, Y., Manabe, T., Inaba, K., Minato, N., Oshima, M., and Taketo, M. M. (2004). Pivotal role of CXCR3 in melanoma cell metastasis to lymph nodes. Cancer Res. 64, 4010-4017.

Kawada, K., and Taketo, M. M. (2011), Significance and mechanism of lymph node metastasis in cancer progression. Cancer Res. 71, 1214-1218.

Keane, M. P., Belperio, J. A., Xue, Y. Y., Burdick, M. D., and Strieter, R. M. (2004). Depletion of CXCR2 inhibits tumor growth and angiogenesis in a murine model of lung cancer. $J$. immunol.172, 2853-2860.

Kim, J., Takeuchi, H., Lam, S. T., Turner, R. R., Wang, H. J., Kuo, C., Foshag, L., Bilchik, A. J., and Hoon, D. S. (2005). Chemokine receptor CXCR4 expression in colorectal cancer patients increases the risk for recurrence and for poor survival. J. Clin. Oncol. 23 , 2744-2753.

Kleinhans, M., Tun-Kyi, A., Gilliet, M. Kadin, M. E., Dummer, R., Burg, G., and Nestle, F. O. (2003). Functional expression of the eotaxin receptor $\mathrm{CCR} 3$ in $\mathrm{CD} 30+$ cutaneous T-cell lymphoma. Blood 101, 1487-1493.

Kodama, J., Hasengaowa Kusumoto, T., Seki, N., Matsuo, T., Ojima, Y., Nakamura, K., Hongo, A., and Hiramatsu, Y. (2007). Association of CXCR4 and CCR7 chemokine receptor expression and lymph node metastasis in human cervical cancer. Ann. Oncol. $18,70-76$.
Kojima, Y., Acar, A., Eaton, E. N., Mellody, K. T., Scheel, C., BenPorath, I., Onder, T. T., Wang, Z. C., Richardson, A. L., Weinberg, R. A., and Orimo, A. (2010). Autocrine TGF-beta and stromal cell-derived factor-1 (SDF-1). Signaling drives the evolution of tumor-promoting mammary stromal myofibroblasts. Proc. Natl. Acad. Sci. U.S.A. 107, 20009-20014.

Kouno, J., Nagai, H., Nagahata, T., Onda, M., Yamaguchi, H., Adachi, K., Takahashi, H., Teramoto, A., and Emi, M. (2004). Up-regulation of CC chemokine, CCL3L1, and receptors, CCR3, CCR5 in human glioblastoma that promotes cell growth. $J$. Neurooncol. 70, 301-307.

Kuil, J., Buckle, T., Yuan, H., van den Berg, N. S., Oishi, S., Fujii, N. Josephson, L., and van Leeuwen, F. W. (2011). Synthesis and evaluation of a bimodal CXCR4 antagonistic peptide. Bioconjug. Chem.

Li, J. Y., Ou, Z. L., Yu, S. J., Gu, X. L., Yang, C., Chen, A. X., Di, G. H., Shen, Z. Z., and Shao, Z. M. (2012). The chemokine receptor CCR4 promotes tumor growth and lung metastasis in breast cancer. Breast Cancer Res. Treat. 131, 837-848.

Li, Y. M., Pan, Y., Wei, Y., Cheng, X., Zhou, B. P., Tan, M., Zhou, X., Xia, W., Hortobagyi, G. N., Yu, D., and Hung, M. C. (2004). Upregulation of CXCR4 is essential for HER2mediated tumor metastasis. Cancer Cell 6, 459-469.

Liang, Z., Wu, T., Lou, H., Yu, X., Taichman, R. S., Lau, S. K., Nie, S., Umbreit, J., and Shim, H. (2004). Inhibition of breast cancer metastasis by selective synthetic polypeptide against CXCR4. Cancer Res. 64, 4302-4308.

Libert, F., Parmentier, M., Lefort, A., Dumont, J. E., and Vassart, G. (1990). Complete nucleotide sequence of a putative $G$ protein coupled receptor: RDC1. Nucleic Acids Res. 18, 1917.

Liu, L., Callahan, M. K., Huang, D., and Ransohoff, R. M. (2005). Chemokine receptor CXCR3: an unexpected enigma. Curr. Top. Dev. Biol. 68, 149-181.

Loberg, R. D., Ying, C., Craig, M., Day, L. L., Sargent, E., Neeley, C., Wojno, K., Snyder, L. A., Yan, L., and Pienta, K. J. (2007). Targeting CCL2 with systemic delivery of neutralizing antibodies induces prostate cancer tumor regression in vivo. Cancer Res. 67, 9417-9424.

Lu, X., and Kang, Y. (2009). Chemokine (C-C motif) ligand 2 engages CCR2+ stromal cells of monocytic 
origin to promote breast cancer metastasis to lung and bone. J. Biol. Chem. 284, 29087-29096.

Lu, Y., Cai, Z., Xiao, G., Liu, Y., Keller, E. T., Yao, Z., and Zhang, J. (2007). CCR2 expression correlates with prostate cancer progression. J. Cell. Biochem. 101, 676-685.

Luker, K. E., and Luker, G. D. (2006). Functions of CXCL12 and CXCR4 in breast cancer. Cancer Lett. 238, 30-41.

Ma, X., Norsworthy, K., Kundu, N., Rodgers, W. H., Gimotty, P. A., Goloubeva, O., Lipsky, M., Li, Y., Holt, D., and Fulton, A. (2009). CXCR3 expression is associated with poor survival in breast cancer and promotes metastasis in a murine model. Mol. Cancer Ther. 8, 490-498.

Mashino, K., Sadanaga, N., Yamaguchi, H., Tanaka, F., Ohta, M., Shibuta, K., Inoue, H., and Mori, M. (2002). Expression of chemokine receptor CCR7 is associated with lymph node metastasis of gastric carcinoma. Cancer Res. 62, 2937-2941.

Maxwell, P. J., Gallagher, R., Seaton, A., Wilson, C., Scullin, P., Pettigrew, J., Stratford, I. J., Williams, K. J., Johnston, P. G., and Waugh, D. J. (2007). HIF-1 and NF-kappaBmediated upregulation of CXCR1 and CXCR2 expression promotes cell survival in hypoxic prostate cancer cells. Oncogene 26, 7333-7345.

Mazzinghi, B., Ronconi, E., Lazzeri, E., Sagrinati, C., Ballerini, L., Angelotti, M. L., Parente, E., Mancina, R., Netti, G. S., Becherucci, F., Gacci, M., Carini, M., Gesualdo, L., Rotondi, M., Maggi, E., Lasagni, L., Serio, M., Romagnani, S., and Romagnani, P. (2008). Essential but differential role for CXCR4 and CXCR7 in the therapeutic homing of human renal progenitor cells. J. Exp. Med. 205, 479-490.

Meincke, M., Tiwari, S., Hattermann, K., Kalthoff, H., and Mentlein, R. (2011). Near-infrared molecular imaging of tumors via chemokine receptors CXCR4 and CXCR7. Clin. Exp. Metastasis 28, 713-720.

Mestas, J., Burdick, M. D., Reckamp, K., Pantuck, A., Figlin, R. A., and Strieter, R. M. (2005). The role of CXCR2/CXCR2 ligand biological axis in renal cell carcinoma. J. immunol.175, 5351-5357.

Miao, Z., Luker, K. E., Summers, B. C., Berahovich, R., Bhojani, M. S., Rehemtulla, A., Kleer, C. G., Essner, J. J., Nasevicius, A., Luker, G. D., Howard, M. C., and Schall, T. J. (2007). CXCR7 (RDC1) promotes breast and lung tumor growth in vivo and is expressed on tumor-associated vasculature. Proc. Natl. Acad. Sci. U.S.A. 104, 15735-15740.

Misra, P., Lebeche, D., Ly, H., Schwarzkopf, M., Diaz, G., Hajjar, R. J., Schecter, A. D., and Frangioni, J. V. (2008). Quantitation of CXCR4 expression in myocardial infarction using 99mTc-labeled SDF-1alpha. J. Nucl. Med. 49, 963-969.

Moser, B., Wolf, M., Walz, A., and Loetscher, P. (2004). Chemokines: multiple levels of leukocyte migration control. Trends Immunol. 25, 75-84.

Mosley, C. A., Wilson, L. J., Wiseman, J. M., Skudlarek, J. W., and Liotta, D. C. (2009). Recent patents regarding the discovery of small molecule CXCR4 antagonists. Expert Opin. Ther. Pat. 19, 23-38.

Muller, A., Homey, B., Soto, H., Ge, N., Catron, D., Buchanan, M. E., McClanahan, T., Murphy, E., Yuan, W., Wagner, S. N., Barrera, J. L., Mohar, A., Verastegui, E., and Zlotnik, A. (2001). Involvement of chemokine receptors in breast cancer metastasis. Nature 410, 50-56.

Muller, A., Sonkoly, E., Eulert, C., Gerber, P. A., Kubitza, R., Schirlau, K., Franken-Kunkel, P., Poremba, C., Snyderman, C., Klotz, L. O., Ruzicka, T., Bier, H., Zlotnik, A., Whiteside, T. L., Homey, B., and Hoffmann, T. K. (2006). Chemokine receptors in head and neck cancer: association with metastatic spread and regulation during chemotherapy. Int. J. Cancer 118, 2147-2157.

Muller, G., Hopken, U. E., and Lipp, M. (2003). The impact of CCR7 and CXCR5 on lymphoid organ development and systemic immunity. Immunol. Rev. 195, 117-135.

Murakami, T., Cardones, A. R., Finkelstein, S. E., Restifo, N. P., Klaunberg, B. A., Nestle, F. O., Castillo, S. S., Dennis, P. A., and Hwang, S. T. (2003). Immune evasion by murine melanoma mediated through CC chemokine receptor-10. J. Exp. Med. 198, 1337-1347.

Murphy, P. M. (2002). International Union of Pharmacology. XXX. Update on chemokine receptor nomenclature. Pharmacol. Rev. 54, 227-229.

Murphy, P. M., Baggiolini, M., Charo, I. F., Hebert, C. A., Horuk, R., Matsushima, K., Miller, L. H., Oppenheim, J. J., and Power, C. A. (2000). International union of pharmacology. XXII. Nomenclature for chemokine receptors. Pharmacol. Rev. 52, 145-176.
Nagasawa, T., Hirota, S., Tachibana, K. Takakura, N., Nishikawa, S., Kitamura, Y., Yoshida, N., Kikutani, H. and Kishimoto, T. (1996). Defects of B-cell lymphopoiesis and bonemarrow myelopoiesis in mice lacking the CXC chemokine PBSF/SDF1. Nature 382, 635-638.

Nimmagadda, S., Pullambhatla, M., and Pomper, M. G. (2009). Immunoimaging of CXCR4 expression in brain tumor xenografts using SPECT/CT. J. Nucl. Med. 50, 1124-1130.

Nimmagadda, S., Pullambhatla, M., Stone, K., Green, G., Bhujwalla, Z. M., and Pomper, M. G. (2010). Molecular imaging of CXCR4 receptor expression in human cancer xenografts with $\left[{ }^{64} \mathrm{Cu}\right] \mathrm{AMD} 3100$ positron emission tomography. Cancer Res. 70, 3935-3944.

Orimo, A., and Weinberg, R. A. (2006). Stromal fibroblasts in cancer: a novel tumor-promoting cell type. Cell Cycle 5, 1597-1601.

Phillips, R. J., Mestas, J., GharaeeKermani, M., Burdick, M. D., Sica, A., Belperio, J. A., Keane, M. P., and Strieter, R. M. (2005). Epidermal growth factor and hypoxia-induced expression of CXC chemokine receptor 4 on non-small cell lung cancer cells is regulated by the phosphatidylinositol 3kinase/PTEN/AKT/mammalian target of rapamycin signaling pathway and activation of hypoxia inducible factor-1alpha. J. Biol. Chem. 280, 22473-22481.

Redjal, N., Chan, J. A., Segal, R. A., and Kung, A. L. (2006). CXCR4 inhibition synergizes with cytotoxic chemotherapy in gliomas. Clin. Cancer Res. 12, 6765-6771.

Rennen, H. J., Frielink, C., Brandt, E., Zaat, S. A., Boerman, O. C., Oyen, W. J., and Corstens, F. H. (2004). Relationship between neutrophil-binding affinity and suitability for infection imaging: comparison of (99m)Tc-labeled NAP-2 (CXCL-7) and 3 C-terminally truncated isoforms. J. Nucl. Med. 45, 1217-1223.

Rhodes, L. V., Short, S. P., Neel, N. F., Salvo, V. A., Zhu, Y., Elliott, S., Wei, Y., Yu, D., Sun, M., Muir, S. E., Fonseca, J. P., Bratton, M. R., Segar, C., Tilghman, S. L., SobolikDelmaire, T., Horton, L. W., ZajaMilatovic, S., Collins-Burow, B. M., Wadsworth, S., Beckman, B. S., Wood, C. E., Fuqua, S. A., Nephew, K. P., Dent, P., Worthylake, R. A., Curiel, T. J., Hung, M. C., Richmond, A., and Burow, M. E. (2011). Cytokine receptor CXCR4 mediates estrogen-independent tumorigenesis, metastasis, and resistance to endocrine therapy in human breast cancer. Cancer Res. 71, 603-613.

Rodero, M., Marie, Y., Coudert, M., Blondet, E., Mokhtari, K., Rousseau, A., Raoul, W., Carpentier, C. Sennlaub, F., Deterre, P., Delattre, J. Y., Debre, P., Sanson, M., and Combadiere, C. (2008). Polymorphism in the microglial cell-mobilizing CX3CR1 gene is associated with survival in patients with glioblastoma. J. Clin. Oncol. 26, 5957-5964.

Rubie, C., Frick, V. O., Ghadjar, P., Wagner, M., Grimm, H., Vicinus, B., Justinger, C., Graeber, S., and Schilling, M. K. (2010). CCL20/CCR6 expression profile in pancreatic cancer. J. Transl. Med. 8 , 45.

Rubie, C., Oliveira-Frick, V., Rau, B., Schilling, M., and Wagner, M. (2006). Chemokine receptor CCR6 expression in colorectal liver metastasis. J. Clin. Oncol. 24, 5173-5174; author reply 5174 .

Salvucci, O., Bouchard, A., Baccarelli, A., Deschenes, J., Sauter, G., Simon, R., Bianchi, R., and Basik, M. (2006). The role of CXCR4 receptor expression in breast cancer: a large tissue microarray study. Breast Cancer Res. Treat. 97, 275-283.

Scala, S., Ottaiano, A., Ascierto, P. A., Cavalli, M., Simeone, E., Giuliano, P., Napolitano, M., Franco, R., Botti, G., and Castello, G. (2005). Expression of CXCR4 predicts poor prognosis in patients with malignant melanoma. Clin. Cancer Res. 11, 1835-1841.

Schimanski, C. C., Schwald, S. Simiantonaki, N., Jayasinghe, C., Gonner, U., Wilsberg, V., Junginger, T., Berger, M. R., Galle, P. R., and Moehler, M. (2005). Effect of chemokine receptors CXCR4 and CCR7 on the metastatic behavior of human colorectal cancer. Clin. Cancer Res. 11, 1743-1750.

Shamaladevi, N., Lyn, D. A., Escudero, D. O., and Lokeshwar, B. L. (2009). CXC receptor-1 silencing inhibits androgen-independent prostate cancer. Cancer Res. 69, 8265-8274.

Shulby, S. A., Dolloff, N. G., Stearns, M. E., Meucci, O., and Fatatis, A. (2004). CX3CR1-fractalkine expression regulates cellular mechanisms involved in adhesion, migration, and survival of human prostate cancer cells. Cancer Res. 64, 4693-4698.

Sierro, F., Biben, C., Martinez-Munoz, L., Mellado, M., Ransohoff, R. M., Li, M., Woehl, B., Leung, H., Groom, J., Batten, M., Harvey, R. P., Martinez, A. C., Mackay, C. R., and Mackay, 
F. (2007). Disrupted cardiac development but normal hematopoiesis in mice deficient in the second CXCL12/SDF-1 receptor, CXCR7. Proc. Natl. Acad. Sci. U.S.A. 104, 14759-14764.

Singh, R., Stockard, C. R., Grizzle, W. E., Lillard, J. W. Jr., and Singh, S. (2011). Expression and histopathological correlation of CCR9 and CCL25 in ovarian cancer. Int. J. Oncol. 39, 373-381.

Singh, S., Singh, A. P., Sharma, B., Owen, L. B., and Singh, R. K. (2010). CXCL8 and its cognate receptors in melanoma progression and metastasis. Future Oncol. 6, 111-116.

Singh, S., Singh, U. P., Stiles, J. K., Grizzle, W. E., and Lillard, J. W. Jr. (2004). Expression and functional role of CCR9 in prostate cancer cell migration and invasion. Clin. Cancer Res. 10, 8743-8750.

Singh, S., Varney, M., and Singh, R. K. (2009a). Host CXCR2-dependent regulation of melanoma growth, angiogenesis, and experimental lung metastasis. Cancer Res. 69, 411-415.

Singh, S., Sadanandam, A., Nannuru, K. C., Varney, M. L., MayerEzell, R., Bond, R., and Singh, R. K. (2009b). Small-molecule antagonists for CXCR2 and CXCR1 inhibit human melanoma growth by decreasing tumor cell proliferation, survival, and angiogenesis. Clin. Cancer Res. 15, 2380-2386.

Singh, S., Nannuru, K. C., Sadanandam, A., Varney, M. L., and Singh, R. K. (2009c). CXCR1 and CXCR2 enhances human melanoma tumourigenesis, growth and invasion. Br. J. Cancer 100, 1638-1646.

Smith, M. C., Luker, K. E., Garbow, J. R., Prior, J. L., Jackson, E., PiwnicaWorms, D., and Luker, G. D. (2004). CXCR4 regulates growth of both primary and metastatic breast cancer. Cancer Res. 64, 8604-8612.

Sun, Y. X., Wang, J., Shelburne, C. E., Lopatin, D. E., Chinnaiyan, A. M., Rubin, M. A., Pienta, K. J., and Taichman, R. S. (2003). Expression of CXCR4 and CXCL12 (SDF-1) in human prostate cancers (PCa) in vivo. J. Cell. Biochem. 89, 462-473.

Tachibana, K., Hirota, S., Iizasa, H., Yoshida, H., Kawabata, K., Kataoka Y., Kitamura, Y., Matsushima, K. Yoshida, N., Nishikawa, S., Kishimoto, T., and Nagasawa, T. (1998). The chemokine receptor CXCR4 is essential for vascularization of the gastrointestinal tract. Nature 393, 591-594.

Takanami, I. (2003). Overexpression of CCR7 mRNA in nonsmall cell lung cancer: correlation with lymph node metastasis. Int. J. Cancer 105, 186-189.

Tamamura, H., Omagari, A., Oishi, S., Kanamoto, T., Yamamoto, N., Peiper, S. C., Nakashima, H., Otaka, A., and Fujii, N. (2000). Pharmacophore identification of a specific CXCR4 inhibitor, T140, leads to development of effective anti-HIV agents with very high selectivity indexes. Bioorg. Med. Chem. Lett. 10, 2633-2637.

Tamamura, H., Tsutsumi, H., and Fujii, N. (2006). The chemokine receptor CXCR4 as a therapeutic target for several diseases. Mini Rev. Med. Chem. 6, 989-995.

Tamamura, H., Xu, Y., Hattori, T., Zhang, X., Arakaki, R., Kanbara, K., Omagari, A., Otaka, A., Ibuka, T., Yamamoto, N., Nakashima, H., and Fujii, N. (1998). A lowmolecular-weight inhibitor against the chemokine receptor CXCR4: a strong anti-HIV peptide T140. Biochem. Biophys. Res. Commun. 253, 877-882.

Teicher, B. A., and Fricker, S. P. (2010). CXCL12 (SDF-1)/CXCR4 pathway in cancer. Clin. Cancer Res. 16, 2927-2931.

Thelen, M., and Thelen, S. (2008). CXCR7, CXCR4 and CXCL12: an eccentric trio? J. Neuroimmunol. 198, 9-13.

Vaday, G. G., Peehl, D. M., Kadam, P. A., and Lawrence, D. M. (2006). Expression of CCL5 (RANTES) and CCR 5 in prostate cancer. Prostate 66, 124-134.
Vallet, S., and Anderson, K. C. (2011). CCR1 as a target for multiple myeloma. Expert Opin. Ther. Target 15, 1037-1047.

Varney, M. L., Johansson, S. L., and Singh, R. K. (2006). Distinct expression of CXCL8 and its receptors CXCR1 and CXCR2 and their association with vessel density and aggressiveness in malignant melanoma. Am. J. Clin. Pathol. 125, 209-216.

Wang, J., Shiozawa, Y., Wang, Y., Jung, Y., Pienta, K. J., Mehra, R., Loberg, R. and Taichman, R. S. (2008). The role of $\mathrm{CXCR7/RDC1}$ as a chemokine receptor for CXCL12/SDF-1 in prostate cancer. J. Biol. Chem. 283, 4283-4294.

Waugh, D. J., and Wilson, C. (2008). The interleukin-8 pathway in cancer. Clin. Cancer Res. 14, 6735-6741.

Weiss, I. D., Jacobson, O., Kiesewetter, D. O., Jacobus, J. P., Szajek, L. P., Chen, X., and Farber, J. M (2012). Positron emission tomography imaging of tumors expressing the human chemokine receptor CXCR4 in mice with the use of ${ }^{64} \mathrm{Cu}$ AMD3100. Mol. Imaging Biol. 14 106-114.

Wijtmans, M., Verzijl, D., Leurs, R., de Esch, I. J., and Smit, M. J. (2008). Towards small-molecule CXCR3 ligands with clinical potential. Chem. Med. Chem. 3, 861-872.

Wiley, H. E., Gonzalez, E. B., Maki, W., Wu, M. T., and Hwang, S. T. (2001). Expression of CC chemokine receptor-7 and regional lymph node metastasis of B16 murine melanoma. J. Natl. Cancer Inst. 93, 1638-1643.

Wolf, M., Delgado, M. B., Jones, S. A., Dewald, B., Clark-Lewis, I., and Baggiolini, M. (1998). Granulocyte chemotactic protein 2 acts via both IL-8 receptors, CXCR1 and CXCR2. Eur. J. Immunol. 28, 164-170.

Wong, D., and Korz, W. (2008). Translating an antagonist of chemokine receptor CXCR4: from bench to bedside. Clin. Cancer Res. 14, 7975-7980.
Woodard, L. E., and Nimmagadda, S. (2011). CXCR4-based imaging agents. J. Nucl. Med. 52, 1665-1669.

Yang, G., Rosen, D. G., Liu, G., Yang, F., Guo, X., Xiao, X., Xue, F., MercadoUribe, I., Huang, J., Lin, S. H., Mills, G. B., and Liu, J. (2010). CXCR2 promotes ovarian cancer growth through dysregulated cell cycle, diminished apoptosis, and enhanced angiogenesis. Clin. Cancer Res. 16, 3875-3886.

Zlotnik, A. (2006). Involvement of chemokine receptors in organspecific metastasis. Contrib. Microbiol. 13, 191-199.

Zlotnik, A., and Yoshie, O. (2000). Chemokines: a new classification system and their role in immunity. Immunity 12, 121-127.

Zlotnik, A., Yoshie, O., and Nomiyama, H. (2006). The chemokine and chemokine receptor superfamilies and their molecular evolution. Genome Biol. 7, 243.

Conflict of Interest Statement: The author declares that the research was conducted in the absence of any commercial or financial relationships that could be construed as a potential conflict of interest.

Received: 16 October 2011; accepted: 24 April 2012; published online: 30 May 2012.

Citation: Nimmagadda S (2012) Differential expression of chemokine receptors and their roles in cancer imaging. Front. Oncol. 2:46. doi: 10.3389/fonc. 2012.00046

This article was submitted to Frontiers in Cancer Imaging and Diagnosis, a specialty of Frontiers in Oncology. Copyright (c) 2012 Nimmagadda. This is an open-access article distributed under the terms of the Creative Commons Attribution Non Commercial License, which permits non-commercial use, distribution, and reproduction in other forums, provided the original authors and source are credited. 